\title{
An Efficient Machine Learning Data Analysis for Outpatients
}

\author{
Nerusu Praneeth, B.Vamsi
}

\begin{abstract}
In partner degree age any place mobile phones and web based life turned into extra powerful than any time in recent memory, the general public of health related crisis responders need utilization of it as of now ever. These days, medical clinics, care focuses, and elective foundations directly offer care for a few physically handicapped and matured patients. For these patients to get the consideration they merit, they have to leave their regions of solace and move to the nearest medical clinic. This contrarily influences the patients' body and impels mental weight. Additionally, these patients could have ailments which may not alter them to go outside alone, and in most noticeably terrible things, these patients could have significant crises that will require restorative consideration. For instance, if a patient includes a systole inside or outside the premises of an emergency clinic, there probably won't be anybody to rapidly show up and help. As of right now, lethal mishaps like these have had a spike in rate. The most disadvantage being moon-looked in these things is that the postponed appearance of medicinal reaction. So, to combat this case, we have a tendency to propose a medical emergency application that enables North American country to observe the vital organ of the patients to supply them medical services in dire thing. This application furthermore gives stockpiling of information of the patients inside the network cloud, builds up the implies that of demonstration with the specialist and get drugs if important.
\end{abstract}

\section{Keywords: Emergency, Medical, Mobile. Etc}

\section{INTRODUCTION}

The use of smart phones has seen a significant increase thanks to its easy use. If this technological marvel was created on the market to each worker and patient within or outside a hospital, then there's a large risk that these patients are going to be offered facilitate within the fastest method doable. Hence, with the usage of Cloud Computing upheld in a very cell phone application, patients will be ready to agree to help from specialists at whatever point and where important.

One of the chief eye catching things in Cloud is that the weight on Cloud Storage. Distributed storage could be an assistance that encourages you to store data by sparing it inside the web or partner degree other system to a disconnected information stockpiling medium kept up by an outsider. Along these lines, the information with respect to the emergency clinic staff and furthermore the patients sheltered and secure, renowned exclusively to the service provider.

During the main 2000s, smart phones were being exclusive and created by the world's driving firms. Anyway at the hour of creation, they were unreasonably dear for the everyday people to look for. Hence, a few were still exploitation pagers for trading information with one another. This proposes of correspondence was wide polished by most

Revised Manuscript Received on October 25, 2019

Nerusu Praneeth, Computer Science and Engineering

B.Vamsi, Computer Science and Engineering clinics, and keeps on being contemplated the standard. This enabled the laborers to quickly give therapeutic reaction and spare lives among a concise separation (Hospital framework).

By extending this concept and implementing it victimization the smart phones we have a tendency to might cowl wider region which can additionally embrace outside the hospital infrastructure. this style the patients UN office are in need of therapeutic consideration will get encourage quicker than expected. in step with 2013 common enrollment data that was released by the CENSUS governing body almost twenty third of all out passings in Asian country had happened owing to no restorative consideration for the duration of the hour of death. Our venture intends to reduce this rate moreover as possible.

To accomplish this, we tend to propose a cell phone application that screens the imperative organ of the patients and find crises as fast as feasible. On the off chance that such crises ar distinguished, the machine sends partner degree ready message close to the patient subtleties to the closest medicinal rescuer that allows the responders to embrace to abstain from squandering the patient as fast as feasible. This application moreover allows the patients to get medicine for drugs from the specialists.

\section{RELATED WORKS}

Shin Yan Chiou et al., planned that the utilization of community cloud is concisely mentioned. A Community Cloud could be a cloud-based info that regularly collects device information from a wise Building, creating this information simply on the market within the event of associate degree emergency. Access restrictions ar applied to supply completely different data roughness for eventualities. within the event of associate degree emergency, the Community Cloud will unharness elaborate data to approved medical workers, providing additional economical rescue operations. [1]

S. Zeadally et al., referenced numerous mysterious validation conventions for Wireless Body space Networks (WBAN) that were wanted to fortify security by defensive the characters of patients and by securely scrambling their information. In any case, these conventions don't appear to be secure enough. In this way, this undertaking advises the client to survey the chief late strategy for WBANs partner degreed connotes that it isn't verify for medicinal applications by directing a pantomime assault. From that point onward, the client proposes a fresh out of the box new AA topic for WBANs and demonstrates that it's safe. The outcomes show North American nation that the arranged subject not exclusively beats the wellbeing shortcomings in past plans anyway moreover has indistinguishable calculation costs at the customer perspective. [2] 
L. Chen et al., planned associate degree economical and privacy-preserving location-based services question theme. during this subject, the area based specialist organization's data ar starting hang on inside the cloud server in partner degree encoded way, and afterward, enlisted client will get right area based assistance question results while not uncovering his/her area information to the area based help provider and furthermore the cloud server. [3]

Adams et al., arranged that getting information all through crisis things experiences generous difficulties, as monstrous volume of learning process, unstructured data, security, endorsed data get to, so forward. Among these issues, get to approval has gotten next to no consideration. To conjointly address similar issues, an area mindful approval subject that grants introductory responders to get to information is speculated, just on the off chance that they're among a predefined good ways from data mortgage holders at the hour of partner degree crisis. [4]

L.- J. Kau et al., arranged partner degree structure for the harvest time mishap identification and relating wide space salvage framework upheld an insightful telephone and furthermore the third era (3G) systems. to comprehend the harvest time recognition, the edges non inheritable by the electronic compass (e-compass) and furthermore the undulation grouping of the tri-hub estimating framework on the great telephone are utilized in light of the fact that the framework inputs. The no inheritable flag at that point acclimated create partner degree requested element succession thus analyzed in a sequential way by the arranged course classifier for acknowledgment reason. When the relating highlight is checked by the classifier at the present state, it enters following state.

Something else, the framework can reset, returning to the underlying state and anticipate another component grouping to look. When partner degree mishap is distinguished, the client's position will be non inheritable by the overall situating framework \&\#40;GPS\&\#41; or the helped GPS, and sent to the salvage focus through a $3 \mathrm{G}$ correspondence system all together that the client will get medicinal encourage as directly as possible. Machine weight and power utilization issue on an insightful correspondence framework is prove to have decreased. Additionally, the pervasiveness of the arranged algorithmic guideline is even by the investigate results, that indicated that a recognized mishap recognition exactness up to ninety two on the affectability and ninety nine. $75 \%$ on the explicitness will be basically accomplished of exercises that are measurable by exploitation the arranged fell classifier. [5]

F. Hoflinger et al., arranged a totally one of a kind indoor limitation and recognition framework bolstered mechanical wonder sensors for crisis responders. The framework utilizes speeding up, precise rate and power field sensors and comprises of 3 primary components. the essential component could be a changed Kalman sifting that executes the gadget data combination and at indistinguishable time, recognizes and limits the power field unsettling influences, to supply an all-inclusive term stable goals. The subsequent component is zero rate change. This resets the speed among still part to convey right position information. The last component of the framework is movement recognition, that is accomplished by canny the general situation of each body area upheld the change of facilitate edge of each body segment. This exploratory outcome shows that the framework is prepared to follow individual inside in each strolling and running cases, and moreover helps screen the body development all through everything of examination. [6] F. Pascucci et al., arranged the REFIRE venture that clarifies that GPS-denied zones come up short on the necessary assets to supply area and right correspondence to the essential responders like chimney responders in indoor situations. to beat this, the REFIRE venture the REFIRE undertaking proposes a framework made out of deployable arrangements misusing modest , straightforward, incredibly institutionalized pre-introduced milestones. The REFIRE task has impressive focuses: to approve such arrangements in practical inevitabilities and to envision the gigantic scope of area information that frameworks ar incapable to work. [7]

J. Rantakokko et al., gave an overview on advances and hypothetical thoughts that may be utilized for salvage situating frameworks, with a weight on indoor situating. a basic and conservative situating framework with consistent inclusion could be a very required for expanding security in crisis things, medicinal and something else. It ought to be light-weight, versatile, modest, and ought to expend lower power, and still offer precision all through time overpowering activities. [8]

\section{PROPOSED SYSTEM}

As indicated by 2013 common enlistment data that was released by the CENSUS top managerial staff almost twenty third of complete passing in Asian country had happened inferable from no medicinal consideration for the duration of the hour of death. Our venture expects to decrease this rate moreover as feasible. To accomplish this, we tend to propose a cell phone application that screens the essential organ of the patients and find crises as fast as feasible. In the event that such crises are identified, the apparatus sends partner degree ready message adjacent to the patient subtleties to the closest medicinal rescuer that allows the responders to embrace to abstain from squandering the patient as fast as feasible. This application furthermore allows the patients to get medicine for meds from the specialists.

Methods
a. Data storage
b. Patient Medication
c. Patient Appointment Request
d. Emergency Monitor and Rescue Aid

In this device, the in order of the considerable number of patients and staff (specialists, medical attendants, ward young men and ambulances) inside the clinic or the association are got and hang on in an extremely regular cloud server data. The laborers will send an enlistment demand alongside their information through the cloud exploitation their great telephone. These information are confirmed by a standard overseer inside the administrator dashboard and if the data are valid, the registration request are going to be accepted associate degreed an worker ID are going to be generated for the individual worker. Solely when receiving associate degree worker ID can the specialist can perform more activities. At the point when the enrollment technique is finished, the client (representative and patient) will 
login in into the apparatus exploitation the username and parole given while enlisting.

\section{IV.SYSTEM ARCHITECTURE}

This work architecture consists of two main entity

a. Patients who are in need medicinal consideration

b. Hospital Employees who present restorative support of the patient if there should arise an occurrence of crises

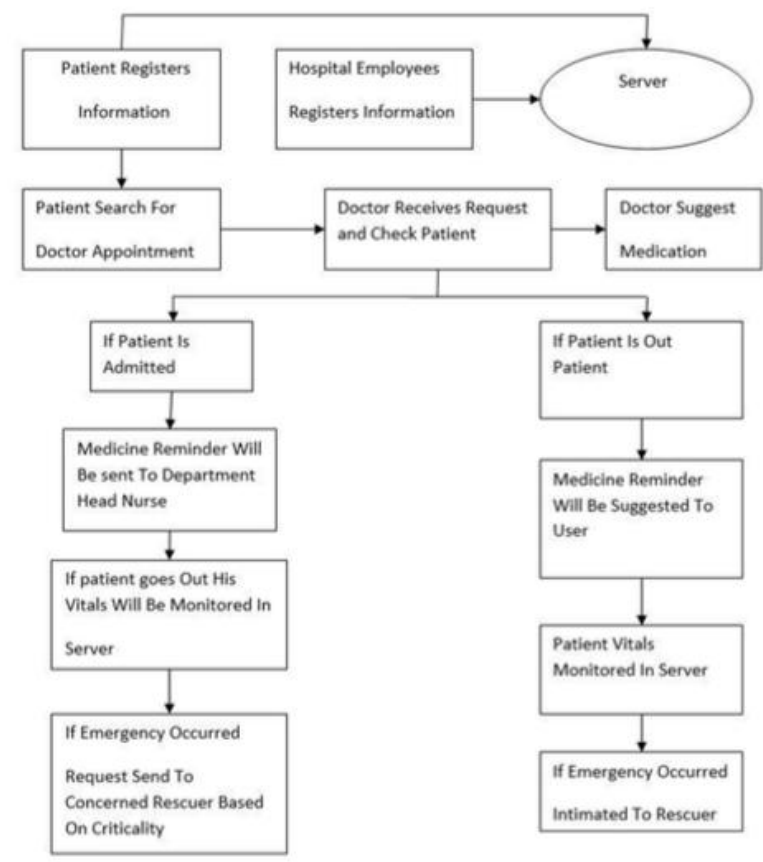

- Our system design includes 2 main entities:

- Patients, UN agency ar in want of medical attention.

- Hospital staff, UN organization offer therapeutic support of the patient just if there should be an occurrence of crises.

\subsection{Medical Emergency System}

All together for the specialists to supply the necessary administrations to the patients, we have a tendency to think about the subsequent precautions:

- The patients ought to be register within the application.

- Each worker of the hospital ought to be registered and be on the market whenever doable.

- The indispensable organ of the patient should be checked circumspectly in the event that he/she is to be spared.

- Misdiagnosis and unfair solution of medicine shouldn't be finished, since this can cause additional hurt than sensible

\section{CONCLUSION}

We develop a medical help crisis to abstain from squandering the lives of patients UN office are conceded or as of late released. It utilizes a cell phone to initiate the essential organ and furthermore the area of a patient by means of BP gadget, vital signs device, and also the GPS device. All the required medical workers are notified of the patient's standing before delivery the patient, so as to be ready. This concept is applicable in hospitals and adulthood homes. This will be applied in individual homes also. Future improvements could grasp moving this administration to cell phones of different in activity frameworks. It ought to also grasp actualizing installment of administration charges for the counseled restorative specialists.

\section{REFERENCES}

1. Shin-Yan Chiou and Zhen-Yuan Liao dynasty, "A time period, automatic and Privacy-Preserving Mobile Emergency-Medical-Service Network for Informing the nearest Rescuer to speedily Support Mobile-Emergency-Call Victims," IEEE Access, vol. 6, pp. 35787 - 35800, 2018

2. D. He, S. Zeadally, N. Kumar, and J.-H. Lee, "Anonymous authentication for wireless body space networks with obvious security," IEEE Syst. J., vol. 11, no. 4, pp. 2590- 2601, Dec. 2017, doi: 10.1109/JSYST. 2016.2544805.

3. H. Zhu, R. Lu, C. Huang, L. Chen, and H. Li, “An economical privacy-preserving location-based services question theme in outsourced cloud," IEEE Trans. Veh. Technol., vol. 65, no.9, pp. 7729-7739, Sep. 2016.

4. H. Ghafghazi, A. Elmougy, H. T. Mouftah, and C. Adams, "Location-aware authorization theme for emergency response," IEEE Access, vol. 4, pp. 4590-4608, 2016.

5. L.-J. Kau and C.-S. Chen, "A good phone-based pocket fall accident detection, positioning, and rescue system," IEEE J. Biomed. Health Inform.,vol. 19, no. 1, pp. 44-56, Jan. 2015.

6. R. Zhang, F. Hoflinger, and L. Reindl, "Inertial device based mostly indoor localization and observance system for emergency responders," IEEE Sensors J., vol. 13, no. 2, pp. 838-848, Feb. 2013.

7. F. Pascucci et al., "A Reference implementation of practical indoor location \& communication systems for First REsponders: The REFIRE project," in Proc. IEEE Int. Symp. Safety, Secur., Rescue golem. (SSRR), Nov. 2012, pp. 1- 5.

8. J. Rantakokko et al., "Accurate and reliable soldier and initial answerer indoor positioning: Multisensor systems and cooperative localization," IEEE Wireless Commun., vol. 18, no. 2, pp. 10-18W

9. S. Bastos, V. Vieira, and A. L. Apolinario, Jr., "Indoor location systems in emergency scenarios: A Survey," in Proc.

10. Annu.Conf. Brazilian Symp. Inf. Syst., Inf. Syst., Comput. Socio-Tech. Perspective, Brazilian Comput. Soc., vol. 1, 2015, p. 34.

11. G. Glanzer, "Personal and first-responder positioning: State of the art and future trends," in Proc. Ubiquitous Positioning, Indoor Navigat., Location based mostly Service (UPINLBS), Oct. 2012, pp. 1-7.

12. L. Berbakov, B. Pavkovic, and S. Vrane, "Smart indoor positioning system for scenario awareness in emergency things," in Proc. 26th Int. Workshop info professional Syst. Appl. (DEXA), Sep. 2015, pp. 139-143.

13. R. Srinivasan, A. Mohan, and P. Srinivasan, "Privacy acutely aware design for rising emergency response in good cities," in Proc. good town Security Privacy Workshop (SCSP-W), vol. 2016, pp. 1-5.

14. D.-M. Do, M.-H.Hyun, and Y.-B. Choi, "RFID-based indoor location recognition system for emergency rescue evacuation support," in Proc. Int. Conf. Grid Pervas.Comput., 2013, pp. 899-906. N. Li, B. Becerik-Gerber, B. Krishnamachari, and L. Soibelman, "A BIM focused indoor localization algorithmic rule to support building fireplace emergency response operations," Automat. Construction, vol. 42, pp. 78-89, Jun. 2014. 
15. B.-S. Nie, W.-X.Chen, L.-K.Wang, R.-M. Zhang, and C. Wang, "Internet of things-based positioning of coalmine personnel and observance of emergency state," in Proc. $2^{\text {nd }}$ Int. Conf. Digit. Manuf. Automat. (ICDMA), Aug. 2011, pp. 657-660.

16. Liutkauskas, D. Matulis, and R. Pleštys, "Location based mostly Services,'"ElektronikaElektrotechnika, vol. 52, no. 3, pp. 35-40, 2004.

17. Amanatiadis, A. Gasteratos, and D. Koulouriotis, "An intelligent multisensor system for initial answerer indoor navigation,” Meas. Sci. Technol., vol. 22, no. 11, p. 114025, Nov. 2011.

18. K. Hari, J.-O. Nilsson, I. Skog, P. Händel, J. Rantakokko, and G. Prateek, "A example of a first-responder indoor localization system,' J. Indian present. Sci., vol. 93, no. 3, pp. 511-520, 2013.

19. G. B. Moon, M. B. Hur, and G.-I.Jee, "An indoor positioning system for a primary answerer in associate degree emergency surroundings," in Proc. 12th Int. Conf. Control, Autom. Syst. (ICCAS), Oct. 2012, pp. 1368-1372.

20. G. B. Moon, S. Chun, M.-B.Hur, and G.-I.Jee, “A sturdy indoor positioning system victimisation two-stage EKF SLAM for initial responders in associate degree emergency surroundings, " in Proc. 13th Int. Conf. Control, Autom. Syst. (ICCAS), Oct. 2013, pp. 707-711. 